\begin{tabular}{c} 
Benha Veterinary Medical Journal \\
$\begin{array}{c}\text { Official Journal Issued by } \\
\text { Faculty of } \\
\text { Veterinary Medicine }\end{array}$ \\
\hline Original Paper
\end{tabular}

\title{
Effect of cetyltrimethylammonium bromide surfactant coated Curcumin copper nanocomposite on hepatocellular carcinoma in rats
}

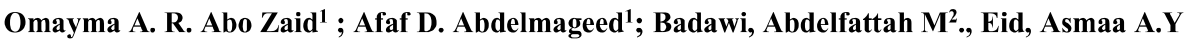

${ }^{1}$ Biochemistry Department., Faculty Veterinary Medicine, Benha University.

${ }^{2}$ Egyptian Petroleum Research Institute

\section{ARTICLE INFO}

Keywords

Hepatocellular carcinome

Cetyltrimethylammonium

bromide

Copper

Curcumin

Diethylnitrosamine

Received 04/12/2019

Accepted 23/02/2020

Available On-Line

18/07/2020

\begin{abstract}
This study was designed to investigate the role of (Curcumin/Copper/ cetyltrimethylammonium bromide) nano particles complex against hepatocellular carcinoma (HCC) induced in rats. Forty rats were divided into four groups. Group 1(negative control group): normal rats. Group 2 (Diethylnitrosamine) (DEN): rats were administrated with DEN ( dose of $20 \mathrm{mg} / \mathrm{kg} \mathrm{b}$. wt.), five times a week $/ 6$ weeks for $\mathrm{HCC}$ induction. Group 3 (protective ): rats were orally treated with Curcumin/CU/CTAB (dissolved in Tween-80 (1\%) in $0.9 \%$ normal saline) at a dose of $35 \mathrm{mg} / \mathrm{kg} \mathrm{b}$. wt., five times a week / 15 weeks as 2 weeks before DEN then, during administration of DEN and 15 weeks after DEN administration. Group 4 ( treated group) rats treated with Curcumin/ CU/ CTAB dissolved in Tween-80 (1\%) in $0.9 \%$ normal saline), at a dose of $35 \mathrm{mg} / \mathrm{kg} \mathrm{b}$. wt., five times a week / 15 weeks, following the administration of DEN for 6 weeks . Injection of DEN induced a significant increase in serum level of alpha-fetoprotein (AFP), alpha-L-fucosidase activity (AFU) and vascular endothelial growth factor (VEGF). On other hand, marked depletion in tissue antioxidants including superoxide dismutase (SOD), glutathione peroxidase (GPX) activities, and reduced glutathione (GSH) concentration. Administration of (Curcumin/ CU/ CTAB) nano composite was able to prevent cellular damage induced by reactive oxygen species (ROS) and able to make changes of tumor markers and tissue antioxidants nearly toward control.
\end{abstract}

\section{INTRODUCTION}

Hepatocellular carcinoma (HCC) is the most common primary liver cancer and has been the third most common cause of death from cancer globally in recent years ( $\mathrm{Li} \mathrm{M}$ et al., 2016). HCC occurs in a number of preexisting conditions that commonly includes hepatitis $\mathrm{C}$ and $\mathrm{B}$, alcoholic and nonalcoholic cirrhosis. It has a poor prognosis after discovery. This had been strongly linked to the hepatitis $\mathrm{C}$ virus epidemic that affected around $10-15 \%$ of the Egyptian population during the last 3 decades and was reported as the highest prevalence of $\mathrm{HCV}$ in the world (Elghazaly et al., 2019).

Diethylnitrosamine (DEN) is a strong hepatocarcinogenic substance that causes disturbances in nucleic acid repair mechanisms and also generates reactive oxygen species (ROS) leading to oxidative stress (Fazal et al., 2017).

Curcumin has been traditionally used in prevention and treatment of several disease. It has been demonstrated that have various health benefits ranging from antiinflammatory and antioxidant to anticarcinogenic properties (Hasima and Aggarwal, 2012).
Studies also indicated that curcumin exerts-hepato-and nephron-protective, and myocardial infarction-protective properties (Aggarwal and Harikumar, 2009).

Copper $(\mathrm{Cu})$ is divalent metal acts as a catalytic cofactor or as an integral component in many vital proteins. Hence, it is an integral structural and functional component in many "cuproproteins" and "cuproenzymes" contributing to numerous biological activities including enzymatic catalysis, scavenging of reactive species, erythropoiesis, pigment formation, iron homeostasis, angiogenesis, immunity, cell to cell communication, and even nerve induction (Denoyer et al., 2015; Rizvi et al ., 2016).

Cetyltrimethylammonium bromide (CTAB) is a quaternary ammonium compound belonging to a group of small molecules known as delocalized lipophilic cations (DLCs). Because of their lipophilic nature and delocalized positive charge, DLCs can penetrate the hydrophobic barriers of plasma and mitochondrial membranes and accumulate in the mitochondria in response to the negative transmembrane potential, resulting in mitochondrial toxicity (zhang et al., 2013).

The aim of this study was conducted to investigate the promising potential value of curcumin in alleviating chemically induced hepatocellular carcinoma in rats and to shed light on its possible mechanisms of action.

\footnotetext{
* Corresponding author: Prof. Omayma A. R. Abo Zaid, Biochemistry Department., Faculty Veterinary Medicine, Benha University.
} 


\section{MATERIAL AND METHODS}

\subsection{Chemicals and reagents}

DEN (purity $\sim 99 \%$ ) was manufactured by Sigma Chemical Co. (St. Louis, Mo, USA) and purchased from Schnelldorf, Germany through the Egyptian International Center for Import Cairo, Egypt. Copper nano gard (purity 99\%) was manufactured by Sigma Chemical Co. (St. Louis, Mo, USA) and purchased from Schnelldorf, Germany through Alfa Acer, Egypt .Nano Curcumin (purity 99\%) was manufactured by national research center, Al-Doky, Egypt. CTAB (purity $\sim 99 \%$ ) was manufactured by Sigma Chemical Co. (St. Louis, Mo, USA) and purchased from Schnelldorf, Germany through the Egyptian International Center for Import Cairo, Egypt.

\subsection{Experimental animal}

Forty adult male Wistar rats, weighting $180-200 \mathrm{gm}$. were used in the experimental investigation of this study, rats obtained from the Laboratory Animals Research Center, Faculty of Veterinary Medicine, Benha University, housed in separate wire mesh cages, exposed to good ventilation, humidity and to a $12-\mathrm{hr}$ light - dark cycle, and provided with a constant supply of standard pellet diet and fresh, clean drinking water ad libitum.

\subsection{Experimental design}

Rats were acclimated to these conditions for 2 weeks before beginning the experiment. After the acclimatization period, the animals were randomly divided into four groups; (10 rats each)

Group (1) Normal healthy animals served as a control group and were orally administered $1-\mathrm{ml}$ vehicle solution (Tween$80(1 \%)$ in $0.9 \%$ normal saline)/rat, five times a week during the whole experimental period (23 weeks).

Group (2) (HCC group) :rats were orally administered DEN with a dose of $20 \mathrm{mg} / \mathrm{kg}$ b. wt., five times a week / 6 weeks (Darwish and El-Boghdady, 2011).

Group (3) (curcumin CU/ CTAB protective group): rats were orally treated with curcumin/ CU / CTAB (dissolved in Tween-80 (1\%) in $0.9 \%$ normal saline) at a dose of 35 $\mathrm{mg} / \mathrm{kg} \mathrm{b}$. wt., five times a week / 15 weeks as 2 weeks before DEN then, during administration of DEN and 15 weeks after DEN administration.

Group (4) (Curcumin/ CU/ CTAB -treated group) : rats treated with Curcumin/ CU/ CTAB dissolved in Tween- 80 ( $1 \%$ ) in $0.9 \%$ normal saline), at a dose of $35 \mathrm{mg} / \mathrm{kg} \mathrm{b}$. wt., five times a week / 15 weeks, following the administration of DEN for 6 weeks, as previously reported by Sreepriya and Bali (2005)

\subsection{Sampling}

2.4.1. Blood samples

After the end of experimental period, rats were fasted overnight and blood samples were collected, under diethyl ether anesthesia, from the retro-orbital venous plexus in centrifuge tubes without any anticoagulant agent to separate the serum samples for the biochemical analysis. Serum levels of alpha-fetoprotein (AFP) rat ELISA kit purchased from MyBiosource, Inc. (USA), catalog no. MBS700622), alpha-L-fucosidase activity (AFU) rat ELISA kit purchased from MyBiosource, Inc. (USA), catalog no. KT-67510), vascular endothelial growth factor (VEGF) rat ELISA kit purchased from MyBiosource, Inc. (USA), catalog no.
MBS843480. according to the manufacturer's instructions provided with assay kits.

\subsubsection{Tissue specimen (liver tissue)}

After finishing blood sampling, rats of each group were sacrificed by cervical decapitation. The abdomen was opened, and the liver specimen was quickly removed and opened gently using a scrapper, cleaned by rinsing with icecold isotonic saline to remove any blood cells, then blotted between 2 filter papers. The samples were prepared in icecold phosphate buffer $(0.1 \mathrm{M}, \mathrm{pH} 7.4)$ using a potterElvehjem homogenizer to give a $10 \%$ homogenates which were used for estimation of liver tissue superoxide dismutase(SOD) by using ELISA kit purchased from MyBiosource, Inc. (USA), catalog no. MBS722675, Glutathione perioxidase (GPX) activities by ELISA kit purchased from MyBiosource, Inc. (USA), catalog no. MBS744364 and reduced glutathione(GSH) by ELISA kit purchased from MyBiosource, Inc. (USA), catalog no. MBS265966. according to the manufacturer's instructions provided with assay kits. These tissue samples were quickly frozen in a deep freezer at $\left(-20^{\circ} \mathrm{C}\right)$ for subsequent biochemical analyses.

\subsection{Statistical analysis}

The SPSS (version 25) was used in data analysis. Data were analyzed with one-way analysis of variance (ANOVA) followed by a post hoc test (Duncan alpha) for multiple comparisons. The data were expressed as mean \pm standard error (S.E). P values $<0.05$ were considered to be statistically significant.

\section{RESULTS}

3.1. Biochemical analyses

The data presented in Table 1 revealed that resulted in significant increase in serum levels of AFP, AFU, and VEGF in HCC group in comparison with the control group. The protective and treatment with (Curcumin/CU/CTAB) showed a significant decrease $(p<0.05)$ in serum levels of AFP, AFU, and VEGF when compared to the untreated HCC group. Interestingly, these results indicated that there was a significant depletion $(\mathrm{p}<0.05)$ in AFP, AFU, and VEGF serum levels in (Curcumin/CU/CTAB) protected and treated group.

Table 1 The impact of prophylactic or therapeutic remedy of (Curcumin/ $\mathrm{Cu}$ CTAB) nano-particles complex on AFP, AFU, and VEGF in hepatocellular carcinoma of rat's model.

\begin{tabular}{|c|c|c|c|}
\hline \multirow[b]{2}{*}{ Groups } & \multicolumn{3}{|c|}{ Parameters } \\
\hline & $\begin{array}{c}\text { AFP } \\
\mathrm{Pg} / \mathrm{ml}\end{array}$ & $\begin{array}{l}\mathrm{AFU} \\
(\mathrm{U} / \mathrm{l})\end{array}$ & $\begin{array}{l}\mathrm{VEGF} \\
\mathrm{Pg} / \mathrm{ml}\end{array}$ \\
\hline G1:Normal control & $12.43 \pm 1.08^{6}$ & $30.87 \pm 0.95^{\mathrm{e}}$ & $34.28 \pm 2.05^{f}$ \\
\hline $\begin{array}{l}\text { G2:diethyl } \\
\text { nitrosamine }(\mathrm{HCC})\end{array}$ & $75.14 \pm 2.49^{a}$ & $158.0 \pm 1.26^{\mathrm{a}}$ & $191.9 \pm 1.52^{\mathrm{a}}$ \\
\hline $\begin{array}{l}\text { G3:HCC+ Curcumin, } \\
\text { Cu, CTAB(TBRP) }\end{array}$ & $30.34 \pm 2.21^{\circ}$ & $61.79 \pm 2.15^{\mathrm{d}}$ & $73.48 \pm 2.72^{\mathrm{d}}$ \\
\hline $\begin{array}{l}\text { G4:HCC+ Curcumin, } \\
\text { Cu,CTAB(TBRT) }\end{array}$ & $\underset{b}{44.48 \pm 3.88}$ & $91.52 \pm 3.27^{\circ}$ & $103.59 \pm 3.87^{\circ}$ \\
\hline
\end{tabular}

\subsection{Liver antioxidant enzymes}

The data presented in Table 2 revealed the effect of the nano composites (Curcumin/ CU/ CTAB) on superoxide dismutase (SOD), glutathione perioxidase (GPX), and reduced glutathione (GSH) activity in the liver DENinduced $\mathrm{HCC}$ in male rat. A high significant decrease in liver 
SOD, GPX and GSH activities was observed in HCC group when compared with the normal control group. protective (TBRP) and treatment with (Curcumin/ CU/ CTAB) nanocomposite exhibited significant decrease $(p<0.05)$ in liver SOD, GPX and GSH activities when compared with the control group.

Table 2 The impact of prophylactic or therapeutic remedy of (Curcumin/ $\mathrm{Cu} /$ $\mathrm{CTAB}$ ) nanoparticles complex on antioxidant enzymes in hepatocellula carcinoma of rat's model.

\begin{tabular}{|c|c|c|c|}
\hline \multirow[b]{2}{*}{ Groups } & \multicolumn{3}{|c|}{ Parameters } \\
\hline & $\begin{array}{r}\mathrm{GSH} \\
\mu \mathrm{g} / \mathrm{ml}\end{array}$ & $\begin{array}{l}\text { SOD } \\
\text { U/L }\end{array}$ & $\begin{array}{l}\text { Gpx } \\
\mathrm{U} / \mathrm{L}\end{array}$ \\
\hline G1: control & $1.97 \pm 0.018^{\mathrm{a}}$ & $72.49 \pm 1.58 \mathrm{a}$ & $25.66 \pm 0.76^{\mathrm{a}}$ \\
\hline G2:diethyl nitrosamine ( $\mathrm{HCC})$ & $0.31 \pm 0.023^{d}$ & $19.34 \pm 0.95^{d}$ & $5.72 \pm 0.31^{e}$ \\
\hline $\begin{array}{l}\mathrm{G} 3: \mathrm{HCC}+\mathrm{Curcumin} / \mathrm{Cu} / \mathrm{CTAB} \\
\text { (TBRP) }\end{array}$ & $1.18 \pm 0.068^{b}$ & $47.4 \pm 2.07^{b}$ & $15.34 \pm 0.91^{\circ}$ \\
\hline $\begin{array}{l}\text { G4:HCC+ Curcumin } \mathrm{Cu} / \mathrm{CTAB} \\
\text { (TBRT) }\end{array}$ & $0.77 \pm 0.05^{\circ}$ & $29.82 \pm 1.65^{\circ}$ & $10.17 \pm 0.53^{a}$ \\
\hline
\end{tabular}

\section{DISCUSSION}

Diethyl nitrosamine (DEN) is a strong hepatocarcinogenic substance that causes disturbances in nucleic acid repair mechanisms and also generates reactive oxygen species (ROS) leading to oxidative stress (Fazal et al., 2017). As such in the present study, we utilized DEN to develop the rat model of HCC. Concerning the result, a significant increase in the serum level of alpha-fetoprotein (AFP), Alpha-Lfucosidase (AFU) and Vascular endothelial growth factor (VEGF) concentration in DEN group when compared with control group. These result similar to (Chen., et al 2012). This finding may be due to increased activity of NF- $\kappa B$ which is known to be implicated in HCC. Regarding the result a significant decrease in serum level of AFP, AFU and VEGF concentration in protected (TBRT) group (Curcumin / $\mathrm{CU} / \mathrm{CTAB}$ ) and treated (TBRP) group (Curcumin/ CU/ CTAB) when compared with DEN group. These result agree with (Hasima and Aggarwal, 2012) and (Mahmoud and ElBessoumy, 2013). This finding may be due to curcumin has excellent antioxidant capacity and anti-carcinogenic properties. Concerning the oxidative parameters, a significant decrease in SOD, GSH and GPx activities in DEN group when compared with control group. These result agreement with (Lin et al., 2007) who demonstrated that overproduction of reactive oxygen species (ROS) plays a key role in the etiology of hepato-carcinoma. ROS could result in oxidative damage of DNA, which facilitate the formation of hepatocellular carcinomas (Abo Zaid et al., 2017).Regarding the oxidative parameters a significant increase in SOD, GSH and GPx activities in protected group (TBRP) (Curcumin/CU/CTAB) and treated group (TBRT) (Curcumin/CU/CTAB) when compared with DEN group (HCC). Regarding to result of nano composite protective and treatment period, might explain that curcumin has excellent capacity and reactive oxygen species (ROS) generation in activated rat peritoneal macrophages (Iqbal et al., 2009). In addition to $\mathrm{Cu}$ can catalyze the generation of reactive species/radicals potentially damaging the macromolecules, namely, proteins, lipids, and nucleic acids (Rizvi et al ., 2016).

\section{CONCLUSION}

The study revealed that nano composite of (Cetyltrimethylammonium bromide, Curcumin/CU/CTAB has a significant anticancer effect against DEN induced hepatocellular carcinoma in rats.

\section{REFERENCES}

1. Abo zaid, O.R., Badawi, A.M., Mahfouz, M.K., and Elwakil, A.A.M., 2017. Biochemical and molecular study on the effect of cetyltrimethylammonium bromide surfactant coated garlic zinc oxide, noval nanocomposite as anti- hepatic carcinogenesis in rats. $\mathrm{Ph}$. $\mathrm{D}$ Thesis Biochemistry. Department. of Vet. Medicine., Benha university. Egypt.

2. Aggarwal, B.B. and Harikumr, K.B., 2009. Potential therapeutic effects of curcumin, the anti-inflammatory agent, against neurodegenerative, cardiovascular, pulmonary, metabolic, autoimmune and neoplastic diseases. Int. J. Biochem. Cell Biol.41: 40-59.

3. Chen, B., Ning, M. and Yang, G., 2012. Effect of paeonol on antioxidant and immune regulatory activity in hepatocellular carcinoma rats. Molecules. 17:4672-83. Chen, L.B. 1988. Mitochondrial membrane potential in living cells. Annu Rev Cell Biol. 4:155-181.

4. Darwish, H.A. and El-Boghdady N.A., 2011. Possible involvement of oxidative stress in diethylnitrosamine induced hepatocarcinogenesis: chemopreventive effect of curcumin. J Food Biochem. 37: 353-61.

5. Denoyer, D.; Masaldan. S.; La Fontaine and Cater M. A., 2015. "Targeting copper in cancer therapy: Copper That Cancer, Metallomics. 7, 11, 1459-1476.

6. Elghazaly, H., Gaballah, A. and BahieEldin, N., 2019. Clinicpathological pattern of hepatocellular carcinoma (HCC) in Egypt. https://academic.oup.com/annonc/article abstract/29/suppl_5/mdy151.018/5039483.

7. Fazal, K., Tariq, J.K., Gauthaman, K., Peter N.P., Adeel, C., Adel, A.; Taha K., Elie, B. and Mohammed A., 2017. Anticancer effects of Ajwa dates (Phoenix dactylifera L.) in diethylnitrosamine induced hepatocellular carcinoma in Wistar rats. Khan et al. BMC Complementary and Alternative Medicine 17:418

8. Hasima, N. and Aggarwal. BB., 2012. Review Article: Cancer-linked targets modulated by curcumin. International Journal of Biochemistry and Molecular Biology 3, 4: 328-351.

9. Iqbal, M.; Okazaki, Y. and Okada, S., 2009. Curcumin attenuates oxidative damage in animal treated with a renal carcinogen , ferric nitrilotriacetate (Fe-NTA):implications for cancer prevention. Mol. Cell. Biochem. 324: 157-164.

10. Li M, Zhang W, Wang B, Gao Y, Song Z, Zheng QC. Ligandbased targeted therapy: A novel strategy for hepatocellular carcinoma. Int. J. Nanomedicine 2016;11:5645-5669.

11. Lin, P.H., Lin C.H., Huang. C.C.; Chuang, M.C. and Lin, P., (2007). 2,3,7,8-Tetrachlorodibenzo-p-dioxin (TCDD) induces oxidative stress, DNA strand breaks, and poly (ADP-ribose) polymerase-1 activation in human breast carcinoma cell lines. Toxicol Lett. 172: 146-58.

12. Mahmoud, E.A. and El-Bessoumy, A.A., 2013. Effect of curcumin on hematological, biochemical and antioxidant parameters in Schistosoma mansoni infected mice. Int J Sci. 2: $1-14$.

13. Rizvi, A., Farhan,M., Naseem. I., and Hadi, M. S., 2016. Calcitriol-copper interaction leads to non enzymatic, reactive oxygen species mediated DNA breakage and modulation of cellular redox scavengers in hepatocellular carcinoma," Apoptosis. 21,. 9,. 997-1007 .

14. Sreepriya, M., and Bali G., 2005. Chemopreventive effects of embelin and curcumin against $\mathrm{N}$ - nitrosodiethylamine phenobarbital-induced hepatocarcinogenesis in Wistar rats. Fitoterapia. 76:549-55.

15. Zhang. L., Wang, L., Hu. Y. ; Lin, Z. ; Tian, Y.; Wu, X., Zhao Y., Chen H., and Wang. Y., 2013. Selective metabolic effects of gold nanorods on normal and cancer cells and their application in anticancer drug screening, Biomaterils, 34, 7117-7126. 